\title{
'N LITERÊRE ASPEK VAN ONS LATYNSE ERFENIS
}

Dit is die Romeine, en by name die veldheer Julius Casesar en sy legioene, wat die "Insula Batavorum" uit die mistige skemering van die prehistorie gehaal het kort voor die begin van die Christelike jaartelling. Hierdie "eiland van die Bataviere" moet verstaan word as die gebied tussen die Waal en die Ryn - die kern van die Lae Lande by die See, die latere staat Nederland. Die Bataviere was een van die baie Germaanse stamme, die ou bewoners van Noordwes-Europa, teen wie die Romeine gestuit het in hulle veroweringstogte. Volgens die Latynse geskiedskrywer Cornelius Tacitus was hulle gedugte vegters maar het vroeg 'n bondgenootskap met die Romeine aangegaan - hoewel daar ook in die verwarring wat in die Ryk gevolg het op die dood van Nero $(68 \mathrm{nC})$, ' $\mathrm{n}$ mislukte opstand van die Bataviere was onder leiding van Cajus Julius Civilis.

Laasgenoemde was, soos sy naam, 'n verromeinste Batavier wat 'n hoë rang in die leer beklee het. Ook die feit dat Bataviere in die tyd van Nero die kern van die keiserlike lyfwag gevorm het, dui op die assimilasieproses wat gevolg het op die Romeinse verowering van ons stamlande. Suidwaarts is die Keltiese Galliërs volkome verromeins, of miskien is verromaans 'n presiese omskrywing, want die Romeinse kultuur en taal het deur inenting op die plaaslike stam 'n nuwe boom met eie bloeisels en vrugte gevorm.

Maar ook in die ou Germaanse gebiede was die Romeinse invloed ingrypend. Vandag nog lewer die Nederlandse bodem oorvloedige bewys daarvan. baggerwerk in hawens en riviermonde, droogleggingsaksies, die grawe van fondamente vir brûe, kanale, geboue. Soms is dit wapentuig wat blootgelê word, byvoorbeeld ' $n$ skild van brons versier met ' $n$ medusakop in reliëf, dan weer 'n hele Romeinse vragskip. Want die Romeine was militêre besetters èn handelslui. Maar die grond lewer ook op 'n goue reukwaterhouer van 'n welgestelde dame, of 'n groen glasfles in die vorm van 'n tros druiwe met die allterkunstige handvatsels en nek. Of dis'n skryfstif, 'n stilus, 'n brons inkpot, of erdewerk vir huishoudelike gebruik.

Naas die militêre nedersettings en handelsposte waarvan daar soveel oorblyfsels is, is ook al blootgelê die plaashuise (villae 
rusticae) en selfs landhuise ( villae urbanae) waarin waarskynlik afgetrede hoë offisiere of administrateurs gewoon het. Hier blyk die verfynde luukse wat die lewe in Rome as voorbeeld gehad het, want aangelegde water in loodwaterpype en versiérde krane is niks ongewoons nie; so ook 'n badhuisie met warm water; en in die woonhuis sentrale verwarming!

Die hele gamma van die Romeinse beskawing was teenwoordig in die Lae Lande, soos blyk uit al die kosbare munte wat opgegrawe word, die beeldjies van gode en godinne, byvoorbeeld dié van Minerva, godin van wysheid en oorlog, wat selfs so ver noord as Friesland gevind is in 'n ou terp - dus 'n opvulling waarop 'n boerehuis gestaan het. Sarkofae en brûe, geboue en paaie is vandag nog monumente van die Romeinse besetting van Europa.

En die primitiewe Germane en Kelte, hoewel aanvanklik bevrees, agterdogtig en in verset, het uiteindelik nie alleen die Pax Romana aanvaar nie, maar gretig gegryp na die kultuur van die hoogsbeskaafde Romeine.

Selfs toe ander en sterker Germaanse stamme oor die Ryksgrense suidwaarts gedring het met die taning van die Romeinse mag en heerkappy, het die assimilasieproses nie opgehou nie. Die Romeine het eers teen die Franke en Saksers geveg, en tog sou dit die Franke wees wat die Latynse kultuur en 'n vervorming van die taal sou laat uitkristalliseer tot 'n oorheersende posisie. Die duidwaarts dringende Franke sou eintlik net hulle Germaanse naam laat leef in die latere Frankryk, want dit was Romaanse gebied, in taal en kultuur.

Die Franke, by name die deel wat genoem word die Wesnederfranke, het ook Nederland oorstroom, maar die Romeinse invloed nie uitgewis nie. Van sowat die vierde eeu af is die gebied verfrankies, maar al die ou vervormde Romeinse plekname, al die woorde in die Nederlandse taal van Latynse herkoms, al die kultuurdinge wat die Romeine gelaat het, het 'n beslissende invloed op die Germaanse Franke benoorde die ou heerweg (leërpad) van Keulen na Boulogne wat die taalgrens vorm, gehad. Ook moet onthou word dat die kerstening van Europa in daardie tyd begin plaasvind het, en nie slegs die taal van die kerk was Latyn nie - dit was deur en deur Rooms, soos sy naam aandui; dus van Rome. Tot selfs die musiek, die sang. Om net een saak te noem: in die Roomse 
kerksang maak die Germaanse Franke nou vir die eerste keer kennis met strofies rymende poësie: reëls met eindrym. Hulle het slegs strafrym geken, dit wil sê allitererende woorde binne dieselfde versreël.

Die Nederlande het veral in die tyd van die Frankiese koning Karel die Grote 'n hegte deel van sy ryk gevorm, en hoewel die Nederlande basies Germaans gebly het in taal en leefwyse, moet 'n mens nie vergeet dat Karel die Grote homself Carolus Magnus laat noem het nie en dat hy in die jaar 800 n C tydens Kersnag in die St Pieterskerk in Rome deur pous Leo III as Keiser van die Romeinse Ryk in die Weste gekroon is.

Die bakermat van die Karolingiese Ryk was die driehoek Aken-Luik-Maastricht (dit word beweer dat Karel aan jig gely het en dat hy die warm bronne waarvan die heilsame uitwerking aan die Romeine bekend was, gereeld moes besoek). In Karel die Grote se tyd kry ons die eerste Frankiese Renaissance, want hy wou nie alleen die ou Romeinse Ryk na militêre en administratiewe prestasies ewenaar nie, maar ook ten opsigte van die hele geestelike en stoflike kultuur. Die Karolingiese beskawing was nie slegs 'n elitêre hofkultuur nie, maar die invloed daarvan is ook in die verwyderde gebiede gevoel. In Utrecht byvoorbeeld het 'n kloosterskool gebloei. Hier het die eerste geskiedeniswerk op Nederlandse bodem ontstaan, die Vita Gregorri deur Luidger, 'n lewensbeskrywing van die grote abt Gregorius van Utrecht.

Na die dood van Karel die Grote het sy hegte ryk uiteengeval en na die eeuelange worstelstryd wat begin het tussen sy seuns Karel die Kale (Frankryk) en Lodewyk die Duitser (Duitsland) om die tussengebied van Lotarius, die derde seun, wat onder meer ook die Nederlande geërf het as deel van die Rynstreek, ontstaan die Boergondiese Kreits met sy sterk verfransende (dus Romaanse) invloed in die Nederlande. Maar so kom ons ook nader aan die tyd van 'n latere Karel, naamlik Keiser Karel die Vyfde, koning van Spanje Keiser van Oostenryk en ook van Nederland. En in die suksessiestryd kom Nederland onder die Spaanse bewind van Karel se seun Filips die Tweede. Dit is die begin van die Nederlandse vryheidstryd, die Tagtigjarige Oorlog wat uitloop op die ongekende ekspansie van Nederland. Die Nederlanders wen nie alleen die oorlog nie, maar ook die Spaanse wêreldhandel, stig 
handelsposte en kolonies oor die hele aardbol, belewe die Goue Eeu van Humanisme, Renaissance en Reformasie.

En daarvan is ons Afrikaanse volk aie resultaat en erfgenaam. Nou weet ek dat die aanvanklike volksplanting direk seker niks ervaar het van die stamlandse Renaissancistiese belangstelling in onder meer die Romeinse taal en kultuur nie, maar in later eeue sou ons altyd weet en ook bewys ons is kinders van die Goue Eeu.

Dit is nie net die Romeins-Hollandse reg wat deur die eeue heen ons erfenis van Rome gebly het nie, maar taal en godsdiens, ons hele stoflike en geestelike kultuur openbaar ons Romeins erfenis. Die Latynse taal mag wel vir ons klassiek, en dood, wees, maar ons Afrikaanse letterkunde bevestig ons Latynse wortels. Daarmee bedoel ek nie slegs dat ons taal vol is van woorde van Latynse herkoms nie, dat oorgelewerde literêre vorme soos die ode en epos vandag nog lewendig is nie, maar dat ons Afrikaanse woordkunstenaars Romeinse materiaal doelbewus benut en sinryke uitdrukkinsmiddel maak.

\section{II}

Benewens vertalings en omdigtings uit verskeie genres van Latynse werke (byvoorbeeld deur Haaroff) is dit by uitstek die grootste van alle Afrikaanse woordkunstenaars, $\mathbf{N} P$ van Wyk Louw, wat in drama en liriek hom gewend het tot die Latynse kultuur en dié literatuurmatig ontgin het: die heidens-Romeinse en die Christelike-Romeinse aspekte daarvan. Hiervan is sy versdrama GERMANICUS (1956), sy digbundels NUWE VERSE (1954) en TRISTIA (1962) die glansryke bevestiging.

In teenstelling met die "donker" visioenere poësie van die voorafgaande bundel GESTALTES EN DIERE (“. . . Donker is my oë en my bloed:/ ek is 'n swart gesteente, en úit / straal niks, en al wat gloed / van binne is, is toegesluit ...") is NUWE VERSE, soos die naam aandui, nie alleen 'n nuwe herbegin in Van Wyk Louw se digterlike oeuvre nie, maar ook 'n bundel vol van die son. Die son en lig en helderte van ons eie land vul die verse, soos Klipwerk getuig, maar ook die son van die Meditereense werklikhid en gedagtewereld, selfs van 


\section{... Voor Christus oor hierdie kalkwêreld van julle kom ween het, voordat die koel en skaduweekloosters uit grys klip wat trane kry, opgetrek is, waar manne gaan skuil het teen julle en téén die Son Onoorwinlik. Om daar die een Son, die helder een van die lewe te hê. (Arlésiennes)}

Die verdringing van die Romeinse "Sol Invictus" deur die nuwe Son, Christus, en die fusie van Romeinse Ryk en die Christendom, die worsteling met ou en nuwe waarhede, vorm die grondslag van die drieluik sonnette: Drie Keiserportrette - drie laat-heidense keisers, Aurelianus, Diocletianus en Galerius. Die Romeinse denk- en waardestrukture wankel, en uit sy nederige oorsprong stoot die Christendom "oor die wal van hierdie ryk van trots."

Die bundel wil duidelik ook wees 'n peiling van die historiese groei van die Christendom via die Romeinse Ryk. Dit begin in Judea, en daarom is daar ook die gedig Die doper in die woestyn wat ons invoer in die gedagtewêreld van Johannes die Doper - ". . . ek is die wag en die verlang . . " - en sy stryd en sy getuienis van die nuwe Lig van die wêreld:

My pad is duister maar ek skreeu en roep die Lig en noem die Weg en breek die laaste eensaam eeu.

Johannes praat ook van "al die watere (wat) straal en soek", en die bundel laat ons ook begryp hoe die Romeinse kultuur die bedding voorberei het waarin dié water kan vloei tot aan die uithoeke van die wêreld.

In hierdie oer-Meditereense wêreld met sy talryke beskawingsen volkerelae mag Christus wel in sekere gevalle 'n "episode en 'n agonie" wees (soos te lese is in die tweede van die met opset genoemde elegiese verse, naamlik Meretrix Tarragonensis), maar die Roomse Kerk dra die Christendom uit, deur sy ordes en kerkvaders en selfs die veroweringe van byvoorbeeld Romaanse volke soos die Spanjaarde. Openbarend in hierdie verband is die twee kort gedigte: Ignatius bid vir sy orde en Die Aquinaat bid vir homself. 
Die bundel bied verder die gesigspunt dat dit hierdie digter se ambag is om hom in en deur sy poësie-maak te besin op die wortels en wese van die Christendom, en dus so van sy eie syn: ". . . dat hierdie kuns van ons ná aan God woon" soos ons lees aan die slot van die eerste van die twee sonnette getitel Die ambag. Die tweede begin so: "Van God durf ek skaars praat: ek ken hom min ..." Vandaar die deemoed by die woordvoerder in hierdie poësie, die piëteitvolle huiwering om die dinge te verwoord - wat weer aan die verse 'n dramatiese spanningskarakter verleen, soos ook die konflik tussen die Romeinse trots en Christelike nederigheid.

Die hooftema en motef van NUWE VERSE is 'n spreke van die ware Sol Invictus in terme van Hebreeuse geskiedenis, maar veral Romeinse verlede en die Afrikaanse hede en werklikheid. Dit bereik 'n hoogtepunt en sintese in die slotgedig van die bundel: Beeld van ' $n$ jeug : duif en perd.

In hierdie gedig werk die digter met drie stukke boustof wat as motiewe dwarsdeur die gedig opereer, wat kristalliseer rondom twee simbole om 'n unieke estetiese struktuur tot stand te bring, wat op sy beurt weer een tema of sentrale idee op die wyse van die woordkuns na vore bring.

Die drie motiewe wat in die opbou van 'n woordkunstige organisme hier gebruik word, is in die eerste plek die digter se jeugherinnering van 'n stukkie Suid-Afrikaanse landelike werklikheid: die seun wat daar in die agterplaas van die dorpswoning in die warm sonskyn, omring van sy duiwe en bewus van die hings in die stal, lees van verbygegane beskawings.

Maar naas hierdie vertroude toneel is daar ' $n$ tweede motief: die Romeinse veroweringe, maar ook die neerlaag by die Trasimene teen Hannibal: die offers wat gebring word aan die Ryk, en per slot van sake aan die Sol Invictus.

Hierdie gedagte van die Romeinse swaard word nóu verbind aan die Kruis, en spesifiek met die Spanjaard Cortes se verowering van die Astekeryk met sy afgodiese menseoffers aan die songod. En dan word binne die blikveld betrek sekere offers sedert "Abel se sterwe by 'n hopie klip", wat oor Abraham en sy seun Isak uitloop op Golgota. 
Die verskeidenheid van stofgegewe - en tog subtiel saamhangend - word saamgetrek in die simbole wat die gedig skep. Daar is wel die swaard, die pyl, die Kruis, maar die dominante simbole is die duif en die perd wat in die titel gesinjaleer word. Teenoor die byna perklose vryheid van die duiwe wat wei en eet, luier en hofmaak, die blou ruim kan inskiet, is daar ook die perd. Wanneer die hings die stal uitgelei word om te kom water drink, ruk hy los, skep chaos in die agterplaas. Maar Bêrend die staljong, ken sy werk en ken sy perd:

Die hings word kort aan sy bek gevat;

en, magtig, gebonde, beheers en mooi,

die stal ingelei; en die grendelhout val vas

En nou is die tema van die gedig ook duidelik. Sentraal staan die gedagtes van die ware vryheid, maar ook skoonheid en harmonie, in gebondenheid. Hierdie vryheid-in-gebondenheid impliseer offer, selfoffer. Dit geld hier sekerlik eerstens kunskepping: "magtig, gebonde, beheers en mooi", maar het 'n wye register van geldigheid. Die basis is religieus en die verwysing na Christus se volkome offer en sy verdonkering van die heidense sonsimbool, is nie verniet nie. Dié daad staan sentraal in skepping en tyd: alles wat voorafgaan, is prefigurasie; alles daarna afskaduwing;

dan op 'n laaste klipkop buite die stad drie kruise oor ' $n$ land wat donker raak, en, eindelik, ' $n$ urye sterwe - en die vermoede: dalk het dit daardie son kon donker maak

sonder verduistering agter ' $n$ maan van klip: omdat die aarde en elke aardgebeurtenis en die son self, en tot die verste ster, tesame net een groot vertelsel is

oor Hom en ons, en deur Hom self vertelvol beeld, prefigurasie, voorbereiding op een voleindigende slot en, dat in elke eeu die-laaste ding verwysig na Hom was, deel van sy Naam...

Die gedig bring nie net struktureel en tematies Rome en Suid-Afrika bymekaar nie, die optiek skuif soms inmekaar: en En ek lees: 
die bruin Romeinse legioene draf uit Rome uit, ál met 'n wit pad langs

- soos Gunsfontein toe - loop die bergklowe af

en word by die onvindbare Trasimene in 'n koel móremis deur die Swart Heer wat eindeloos geduldig is en wys, ingewag, uitoorlê, vasgekeer,

en soos nooit g'n leër nie, gewan... .

Sulla met sy blou en hopelose ö̈;

Pompeius, die dwaas, Crassus die ryke;

dan Julius vol van die mededoë

van 'n versadigde, verstandige mens . . .

En so dramatiseer die verse voor ons oë ons Latynse erfenis, sien ons ons tyd, ruimte en gebeure gesilhoëtteer teen die Romeinse verlede, word die verse simbool van die groei van nuwe lote uit die ou kultuurstam. Ook ander gedigte, naas stof en tema, konkretiseer in hul vorm die klassieke inslag daarvan: die sonnet, die elegie. Selfs tot in fynste vesels van die verse pols die Latynse lewensbloed, soos die aanvangsverse van die sonnet Clifton ons laat besef as ons die geimpliseerde verwysing herken.

Maar watter van die gode sal ek prys dat hierdie winterglans en hierdie dag sowat van wit en goud en deurskyn-grys voor hierdie oog laat speel?

Vergelyk hiermee Horatius: ODES, Boek 1, nr. 12 reëls $1-3$ "Clio, watter man of halwe-god kies jy om te prys met die lier of skerp fluit, of watter god?"

\section{III}

GERMANICUS sluit in vele opsigte aan by NUWE VERSE en dramatiseer in versvorm die lewe van die historiese veldheer-digter Germanicus ( 15 v C $-19 \mathrm{n} \mathrm{C}$ ). Hy was die seun van Drusus, die eerste Germanicus, en die aangenome kind van sy oom Tiberius wat na Augustus Octavius (63 v C -14 n C, keiser in Rome geword het. Dit is uit die geskiedenis be- 
kend dat die jong Germanicus in die jare $14-17 \mathrm{n} \mathrm{C}$ suksesvolle togte teen die Germane aan die Ryngrens van die Ryk onderneem het. In $17 \mathrm{n} \mathrm{C}$ is hy uit naywer deur Tiberius teruggeroep en na die Ooste gestuur waar hy in Antochië sterf, waarskynlik deur geleidelike vergiftiging.

Die drama is met agt tonele opgebou, elk 'n gelade kern en 'n hoogtepunt en beslissingsmoment in die lewe van Germanicus. Die eerste vier tonele speel af in Germanië, in die buurt van Noord-Frankryk, naby die huidige Nederlande. In die openingstoneel is die hoofsaak dat die legioene van hulle geliefde veldheer verwag dat hy met hulle na Rome moet opruk, 'n staatsgreep uitvoer en self heers. Nadat dit bekend geword het dat Augustus gesterf het en die korrupte Livia Augusta en haar seun Tiberius heers, word die aandrang dat Germanicus handelend moet optree, nog sterker.

In die tweede toneel word die sameswering van die offisiere onder leiding van die vurige Republikein, Piso, gebeeld. Hulle vestig hul hoop vir 'n suiwering van die Ryk op Germanicus. Maar Lucius sien in dat hy geen daadmens is nie; trouens, dié nag voor die veldslag teen die Germane, is Germanicus besig om Aratus te vertaal.

In die volgende toneel tree die energieke en aktiewe eggenote Agrippina teenoor haar man Germanicus op, spoor hom aan, maar hy erken "daar loop so baie barste deur my wil". Die vierde toneel toon Germanicus se menslike optrede teen oor sy Germaanse gevangenes, in besonder die vrou Thusnelda.

Tonele vyf en ses speel af enkele maande later in Rome. Nou word bekend die korrupsie en onmenslikheid van Livia, die dierlike ruheid van Tiberius. Germanicus wil nie in die Ooste gaan heers nie, maar omdat hy, soos in Germanië,plig bo eiebelang en ambisie stel, sê hy:

\section{Ek neem dit aan.}

En vat dit soos ek ook die dood aanuaar en al wat menslik is.

Dis dramaties-ironiese woorde, want die sewende en agste tonele toon sy aftakeling en dood deur vergiftiging. In 'n botsing met Piso by die feesmaal van die Nabataiers verdedig hy billikheid teenoor geweld, maar Piso verwyt hom dat hy 
"jonk-oud, swak en slap" geword het, artiest. In die slottoneel vlak voor sy sterwe, breek die tragiese oomblik vir Germanicus aan dat hy insien hoe hy verkeerd gestrewe het:

$E k$ was te helder

'n Mens moet ook modderig wees

as jy wil mens-wees - óf as jy wil heers

Hy het dus in sy eie oë as mens en heerser gefaal. Heerser wou hy nie wees nie - mens wel in al sy konsekwensies. Dit is dan ook die sentrale tema van die stuk waarvan die handeling, ironies maar ook veelseggend, gestu word deur Germanicus se weiering juis om te handel, daadwerklik op te tree. Hy demonstreer so juis die deemoed teenoor die daad, die menslike teenoor die tirannieke. As humanis kom hy te staan teenoor heersers, as denker teenoor daadmense, as kunstenaar teenoor geweldenaars.

Hierdie digterlike en wysgerige mens erf die verantwoordelikheid om te veg en te heers. Hy aanvaar sy plig, maar deel aan korrupsie en intrige wil hy nie hê nie. Daarom trek hy hom in sy onwil in dadeloosheid terug en veroorsaak so sy ondergang. Hy wil nie 'n koninkryk van hierdie wêreld hê nie.

Hierdie woorde, ontleen aan die uitspraak van Jesus Christus gebruik ek doelbewus omdat hierdie drama in terme van menslike optrede ons 'n religieuse ervaring bied. Germanicus is nie slegs ' $n$ oorgangsfiguur tussen die tyd van paganistiese geweld en Christelike menslikheid nie, sy lewensjare het nie slegs ' $n$ toevallige ooreenkoms met dié van Jesus nie, maar die waardes, byvoorbeeld liefde en menslikheid wat hy huldig en die martelaarsfiguur wat hy word, laat onwillekeurig parallelle ontstaan.

Soos daar 'n strukturele patroon is in die voeging van die agt tonele ten opsig van handeling, plek, tyd en figure, so is daar ook ' $n$ beplande ooreenkoms tussen gebeure en woorde in die lewe van Germanicus en dié van Christus. Die keuse waarvoor Germanicus aanvanklik gestel word om 'n staatsgreep te lei en as keiser te heers, het raakpunte met die versoeking in die woestyn. Die laaste maaltyd saam met sy vriende en offisiere wanneer hy klaar besluit het om nie die weg van geweld te volg nie, herinner aan die Laaste Avondmaal. Ook Germanicus maak hier sy "testament": 
Laat hierdie dinge nou ons teken wees in die kouer jare:

(Haal sy swaard af en gee dit aan Piso) Piso - my swaard: hy's stil en skerp en trou en hou sy raad geheim in hierdie skede; neem hom en dra hom en vergeet hom nooit.

(Vir Marcus)

Marcus - neem jy my lyfband: hy's ru maar taai;

laat hy ons bind asof sy koper gesper altwee ons lywe in sy kring omsluit.

(Vir Caius)

Caius, hier is my mantel: hy's nie sag soos hulle in Rome dra nie; hy het die reent in swaarder nagte weggehou; laat hy

ons liefde teen die wêreld warm houen dink aan my.

Vir Lucius kan ek niks gee, Hy't áls geskenk en ons so arm gemaak dat ons nou niks as trane sal kan bring nie.

\section{CAIUS}

Ek dank jou soos ek áls aan jou te dank het. Maar dis droewig, daar's iets ontsettends nou ... dis byna of jy sterwe - hierdie weg-gee.

Germanicus se triomftog in Rome na die oorwinning oor die Germane vind sy parallel in die intog in Jerusalem, soos sy konfrontasie met Tiberius weer Jesus se verhoor resoneer, voor die Joodse Raad, voor Pontius Pilatus. Op die ooreenkoms van die offerdood ter wille van 'n hoë geestelike ideaal het ek reeds gewys. Germanicus sien homself weldeeglik aan die einde as ' $n$ tragiese maar ook 'n noodlotsfiguur. Noodlot in die $\sin$ van voorbestemming. Nie net weens sy kortsigtigheid en tekortkominge het hy homself en andere te gronde gerig nie, maar hy en hulle is te gronde gerig deur die "tyd": as simbool van die onbegryplike-en onstuitbare gang van die wêreld, hier die oorgang van heers met Romeinse geweld tot Christelike liefde. 
In TRISTIA kry ons ' $n$ verdere besinning op en verdieping in die voortgang en ontplooing van die vroeë Christendom langs die weg van Rome, soos ek weldra sal aantoon. Nou val die aksente net anders as in NUWE VERSE met sy tema van heidense sol invictus teenoor die eintlike Sol Invictus, of die onwetende oorgang wat die Germanicusfiguur konkretiseer: die uitreik van die wêreld na 'n nuwe lewenskode.

Die titel TRISTIA is 'n toespelling op die klaagverse, TRISTIA en EPISTULAE EX PONTO, wat die Latynse digter Ovidius geskryf het vanuit sy ballingsoord aan die Swartsee (Pontus). Die toepaslikheid van dié naam wat die Afrikaanse digter gaan leen uit 'n kultuur waarin hy blykens sy vorige werk geinteresseerd geraak het en wat hy as beeldingsmateriaal van universele en tydlose waarhede, én spieëlbeelde vir eie tyd kreatief kon benut, is duidelik. Hierdie verse ontstaan in die jare $1950-1957$ tydens N P van Wyk Louw se Nederlandse "ballingskap", die tyd toe hy hoogleraar in die Afrikaanse letterkunde en kultuur was aan die Gemeentelike Universiteit van Amsterdam. Trouens, die laaste gedig van die eerste afdeling "Verse", nr LXXX, Tristia en haar voyou, begin soos volg: "Wat? Speel hy ballinkie in Pontus? dit wil die Latiniste weet." Dan volg die afdeling getitel "Tristia", met as kwalifikasie daarby: "elegiese verse".

Triest, winters, noordelik - dit sê en suggereer die titel, maar dan in meer as geograiese sin.

Die hele ervaringswêreld van die digter wat in die bundel neerslag vind, het kouer en triestiger geword. Veral wanneer 'n mens in gedagte hou NUWE VERSE met sy son en warm aardsheid. Die verse van TRISTIA sluit in toonaard eerder aan by die slotstemming van GERMANICUS. Geen wonder dus nie dat die woorde op die stofomslag verwys na die klaagsange wat Ovidius rig tot sy vriende in die warm Rome. Afgedruk in Latyn is vier reëls, $9-12$, uit Elegie $X$ van TRISTIA III wat, vry vertaal, soos volg lees: "Maar wanneer die somber winter sy ruwe gelaat vertoon en die wêreld lê onder ys, hard soos marmer, en wanneer jy die noordewind gewaar en die sneeu wat opgesweep word onder die Beersterregroep, dan besef $j y$ dat hierdie volkere hulle naby bevind aan die bibberende pool." 
Dis maar 'n enkele keer dat daar van son en warmte sprake is in Van Wyk Louw se TRISTIA-bundel, en dan ook wel so soos in Satanhelios waar die toneel 'n egte stukkie Africana is.

Maar dis ook duidelik dat net soos Ovidius se gedagtes steeds by Rome is, gebruik Van Wyk Louw sy "noordelike stof" om Suid-Afrika in reliëf te bring. Noorde en suide relativeer mekaar in hierdie verse, soos ook Latyns-Christelike (Roomse) verlede en Germaans Protestanse hede. Dit blyk byvoorbeeld uit 'n gediggie soos $\mathrm{H}$ Petrus waarvan die volle betekenis die 'n mens tergend ontglip, al weet jy ook $\mathrm{H}$ Petrus sou kon slaan op die Rooms-Katolieke kerk en dat die beeld van die jakkals wat grawe in die sneeu, ontleen is aan Joyce se Ulysses.

'n Jakkals grawe in die sneeu
hy's rooi en spikkel teen die wit
en skrik en luister stywe-oor
na êrens-op-die-werf se spit.

My land, my dor, verlate land:

Iets wens olywe groei in jou:

dat alles klein, Latyns, gaan word

en kalk-wit kerkies bou.

Die jakkals grawe in die son,

hy skop ' $n$ bietjie nugter wit

rondom sy agterboudjies uit.

En Dowe-Peet hou aan met spit.

In die konteks van die bundel sou dit nie vergesog wees om in die jakkals ' $n$ beeld van die digter, en in hierdiegeval N P van Wyk Louw, te sien nie. Daarom ook die Afrikaanse term "jakkals", en nie die Europese vos nie. Dis mos juis wat die digter in hierdie bundel laat neerslag vind: sy "grawe in die sneeu" van Europa na die verlede, die ondergrond, ook van ons Christelike erfenis. En terwyl hy met hierdie aktiwiteit besig is, met lees oor die vroeë Christelike kerk, word hy bewus van 'n ander werksaamheid op hierdie "werf"; hy grawe so 'n bietjie, maar elders word daar gespit - planmatig, aanhoudend gearbei.

$\mathrm{Hy}$ is dadelik bewus van die aard van hierdie arbeid. Daarom gaan sy gedagte in die tweede strofe terug na sy eie land, wens hy sy eie land 'n bepaalde soort Christelikheid toe. Die woor- 
de "olywe", "klein Latyns" en "kalkwit kerkies" suggereer (want die eerste strofe het ons geleer om nie letterlik te lees nie, maar simboliserend) 'n Christelike godsdiens van mildheid, intimiteit, warmte. Miskien minder abstrak dogmaties. Meer in "menslike terme". Dis of die digter die Protestantisme (Calvinisme) van sy "dor, verlate land" kontrasteer met die "warmer" Rooms-Katolisisme, of wel ook van die priller vroeë Christendom van die Meditereense streek, en ook verder in Europa, toe die kerk nog meer Latyns en minder rasioneel Germaans was.

In die slotstrofe keer die beeld van die jakkals terug, maar hy grawe nie net in die sneeu in nie, maar ook terwyl die son op hom skyn. Daar is lig, daar is nog ook warmte. Die bewussyn van 'n ander aktiwiteit wat hy aanvanklik met skrik waargeneem het, eintlik van bewus geword het, daardie vonds van die verlede wat hy opgrawe, skop hy as't ware ongeërg, nugter uit vir ons om te sien. En as ons bewus is van die kontras wat hy gevind het tussen wat skynbaar onder die doodse sneeu van Europa begrawe lê, die vroeë Christendom, teenoor dié-van die hede in ons land, dan sluit die gedig ook af met die stelling dat "Dowe-Peet hou aan met spit".

Daardie Christendom van vroeëre tye in Europa werk nog voort in die onophoudelike bearbeiding van die huidige Rooms-Katolieke Kerk. Dowe-Peet is 'n volkse vorm. Dis die Roomse Kerk van die gewone mense, of dan die Roomse Kerk wat vir die mense van die volk nog intiem en vertroulik is. Die "dowe" slaan nie op blote hardhorendheid nie. Hy hou hom doof, hy gaan sy gang, doen sy werk, ongeag alles, arbei voort. Nou is die titel ook duidelik: Heilige Petrus slaan op die Kerk van Rome - dis 'n soort amptelike naam en staan wesenlik gelyk aan die volkse, intieme, warme, "klein-Latynse" Dowe-Peet.

Miskien sou 'n mens die gedig ook ruimer moet lees as slaande op die Roomse Kerk. Heilige Petrus - Dowe Peet is eerder die Christendom, daardie Christendom wat begin het of beslag gekry het met die apostel Petrus in Rome. Dit het versprei via Rome en het wel die Roomse Kerk geword in

Europa. Maar wat die gedig wil releveer, is die Christendom as sodanig, die vroeë en eenvoudige Christendom wat tog nog steeds voortarbei ongeag die "sneeu" (toegesneeudheid) met 
sy koue en doodsheid, iets bewaar van sy vroeë warmte, intimiteit, menslikheid, ongeag die Roomse vorm wat dit aangenaam en in suidelike Europa vandag nog handhaaf.

Die gedig demonstreer dus hoe, deur materiaalstrukturering, waameming visie word. Die waarneming is dus dié jakkals wat in die sneeu grawe, met net buite die blikveld van die waarnemer, maar hoorbaar vir die tuinier of landbouer wat spit: Dowe-Peet. Die visie of implikasie van die waarneming is die digter se soekbedrywigheid na die oorspronge van die Christendom in daardie noordelike Europese wêreld, en sy bewuswording van hoe daardie Christendom nog steeds werk - en dan die wens dat ook in sy eie land iets van die oorspronklike eienskappe van die Christendom bewaarheid mag word.

Nie al die verse is elegies nie soos die volle titel ook aandui: TRISTIA EN ANDER VERSE, VOORSPELE EN VLUGTE, maar deurgaans is daar 'n geryptheid, 'n besonkenheid. Meer selfs as die vorige bundels is die verse van TRISTIA neerslaag van die denke, "die baie-fyn dink"; dus "filosofiese" poësie met 'n sterk religieuse inslag.

Slegs een tematiese struktuuraspek van die bundel wil ek effens toelig: die Latyns-Christelike. 'n Hele paar titels van gedigte is Latyn, soos Ex unquine leonem waarin hierdie sleutelstrofe tot die wesensaard van die TRISTIA-poësie voorkom.

Wat ek van mense of van God wil neem, word in my dofheid dof.-

Iets staan in sterre-en-helderte' geskryf: en ek skryf ná in stof.

Dit is opvallend dat hierdie Latynse titels, soos ook In simplicitate cordis en Ars spoetica eintlik spreekwoordelik is en dui op die gewortelheid van ons Germaanse kultuur in die Latynse, die spontane assimilasie van Romeinse erfgoed, via die kuns (letterkunde) en via die godsdiens.

Kuns en Kerk het van die begin van die Roomse Christendom soos elders en in ander godsdienste, heg met mekaar verweef saamgegaan. Daarom is dit ook nie verwonderlik nie dat onder die gedigte oor kuns en kunstenaars in Van Wyk Louw se bundel iemand soos Piero della Francesca figureer as opskrif van 'n vers. Hierdie Italiaanse skilder uit die vyftiende eeu is 
die woordvoerder in die gedig, en hy verwys ook na Fra Giovanni Angelico, skilder en monnik, 'n ouer tydgenoot.

Verder is daar ook gedigte oor kerkvorste, soos Otto de Visconti, aarsbiskop van Milaan wat "veraartsbiskop vergeet en verdiskonteer / en verskop geraak' $t$ " of Pous Innocentius III. $\mathrm{Hy}$, soos die gedig afsluit, "vier nog groot / en (nét nie heilig) Rooms plus Romeins sy dood." Of daar is die vers nr LXX oor die rooi kardinale. En dan is daar dié verse oor heiliges, byvoorbeeld Dood van die Heilige Biblis, $H$. Teresa van Avila flap uit, $H$. Dominicus en ander martelare en heiliges wat genoem word in LIX. Ook die verhouding Keiser en Kerk lê ten grondslag aan verse soos dié oor Konradyn, die laaste Hohenstauffer (Goue Klein-Leeu), en Keiserlike reskrip.

Laasgenoemde gedig is om verskeie redes interessant. Dit verwerk 'n stukkie vroeë Christelike geskiedenis, want in die reskrip (natuurlik in Latyn) verklaar Constantinius Augustus dat na oorlegpleging, hy en Licinius Augustus besluit het dat alle vroeëre edikte (dus beperkende maatreëls teen die Christene) verval en dat

......... aan genoemde

korporasie van die kristene in die vervolg

die grootste moontlike aandag bestee (moet word);

op hierdie wyse word 'n godheid dalk goedgunstig.

Van Wyk Louw se bron in hierdie en andere van die genoemde gedigte was die Nederlandse vertaling van Eusebius se in Latyn geskrewe kerkgeskiedenis (Eusebius' Kerkelijke Geschiedenia ingeleid en vertaald deur P Dr Desiderius Frances O F M), aldus dr P G du Plessis in STANDPUNTE 65. Lê 'n mens die gedig Keiserlike reskrip naas die ooreenstemmende passasie in die Nederlandse kerkgeskiedeniswerk, val dit op hoe woordelik die die ooreenkoms is, en tog maak Van Wyk Louw 'n omdigting, selekteer hy op subtiele wyse, konstitueer hy 'n nuwe ritmiese en strofiese organisasie van die woorde, skep hy 'n nuwe toonaard omdat hy die oorspronklike ombuig tot die ironiese.

En juis hierdie nuwe element van die ironiese impliseer afstand, die afstand van die Christen van vandag wat terugkyk, glimlaggend, op die amptelike grootdoenerigheid maar wesenlik magteloosheid van die Romeinse keiser teenoor die op- 
komende Christendom. Die keiser probeer die skyn van mag bewaar deur sy hoogdrawende kanselarytaal, maar hy gee toe, verwag selfs guns van dié godheid.

Nie net na inhoud is dit in hoë mate 'n "Latynse" bundel nie, maar ook die twee magtige odes, in afsonderlike afdeling spesifiek so genoem, bevestig die klassieke groeibodem van hierdie poësie wat vorm betref: Hongarye: November 1956 en Groot Ode. Naas die uiterlike vorm van gedigte soos hierdie, sou 'n mens ook die deurgaans rymloosheid van die gedigte in die bundel kon terugvoer na klassieke beinvloeding 'n voorliefde vir ander verskonstituerende middele as eindrym, en wel ritme. Daarby juis die lang reël wat oorwegend voorkom, en die besonke, gerypte toonaard. Daar is deurgaans 'n klassieke ewewigtigheid, Die byna ondefinieerbare watermerk van "Masze und Gröze", so eie aan die Latynse oudheid.

P D VAN DER WALT

$\mathrm{P} \mathrm{U}$ vir $\mathrm{C} \mathrm{HO}$. 